\title{
Curriculum framework for employability readiness skills: sustainable industry engagement
}

\author{
A Azman Arshad ${ }^{1}$, Roseman Mat Jidin ${ }^{1}$, Mohd Firdauz Mhd Radzi ${ }^{1}$. \\ ${ }^{1}$ Program and Institution Planning Division Ministry of Education
}

\begin{tabular}{l}
\hline Article Info \\
\hline Article history: \\
Received Jan $9^{\text {th }}, 2020$ \\
Revised Feb $18^{\text {th }}, 2020$ \\
Accepted Mar $21^{\text {th }}, 2020$ \\
\hline
\end{tabular}

\section{Keyword:}

Readiness Skills,

Employability,

Employment,

WBL,

Industry Engangement

\begin{abstract}
In spite of endeavors to expand the idea of graduate employability, there stays an overall spotlight on creating industry-pertinent employability abilities. The Work- Based Learning approach is found completely catch the multifaceted nature of graduate work-availability. This paper contends for the reclassifying of graduate employability by grasping industrial skills development and identifies with a comprehension of and association with the aptitudes, characteristics, lead, culture and belief system of an expected calling. The partnership model is attracted upon to show how WBL can be designed and created during internship by involving curriculum reform and mapping. The aim of this study is to reduce the skills gap between institution and industry by designing additional curriculum. These programmes are viewed as significant in light of the fact that they encourage students' access to work-based learning activities in polytechnics and work-based opportunities such as placements after completed the internship.
\end{abstract}

C 2020 The Authors. Published by Redwhitepress.

This is an open access article under the CC BY-NC-SA license

(https://creativecommons.org/licenses/by-nc-sa/4.0/

\section{Corresponding Author:}

\section{A Azman Arshad,}

Program and Institution Planning Division Ministry of Education

Email: aazman.arshad@moe.gov.my

\section{Introduction}

In the 21st century, colleges in all around the world are confronting new challenges. Burke, Scurry, Blenkinsopp, \& Graley, (2016) explain about international there has been a growing emphasis on the role of higher education institutions (HEI) in enabling employability and graduate employment, as evidenced by the rise of university graduate employment destinations as an important proxy measure of the value of a university education. Thus, studies in curriculum and curriculum design become essential and immediate which influences the extent to which curriculum, pedagogy and assessment are relevant to the needs of those undertaking particular educational programs.The nature of curriculum which is dynamic has gained considerable attention from international scholars. A number of studies worldwide implies agreement on the nature of curriculum that is indeterminate, unpredictable, and therefore, complex (e.g. Kelly, 2009; McKernan, 2008).

Today's economy demands a better educated workforce than ever before, and jobs in this new economy require more complex knowledge and skills than the jobs of the past. In United States Betsy, Andrew, \& Andrea, (2013) stated to make sure the students from higher educational institution (HEI) gain the skills 
needed to rebuild the economy and meet workforce demands, contextual learning is enforce to help students see the relevance of what they are learning and its connection to career opportunities and life goals. These pathways and programs also can provide innovative options for supporting students with different learning styles. It is supported by previous study by (Plank, DeLuca, \& Estacion, 2005) shows that these kind of programs reduce dropout rates; encourage participation in postsecondary education; and enable students to earn dual enrollment credits, industry-endorsed certificates, and technical endorsements on diploma in engineering.

In Malaysia, rapid changes of the technology and the industries has developed a request for vocational and training institute to produce graduates who are able to compete in an era of globalization (Eric, 2009). Malaysia's economic planning unit (EPU,2006) argued that Malaysia should improve and enhance the quality of the workforce by increasing the educated and skilled human capital. In conjunction with this intention, the government has implemented a number of training programmes to reduce mismatch and gap among students with the needs of the workforce in technical sector of the industry. To preserve the human capital development, emphasis is given to the holistical development including knowledge and skills as well as forming the personality and good moral character. This is consistent with the mission and vision of the transformation of Department of Polytechnic and Community College Education (DPCCE).

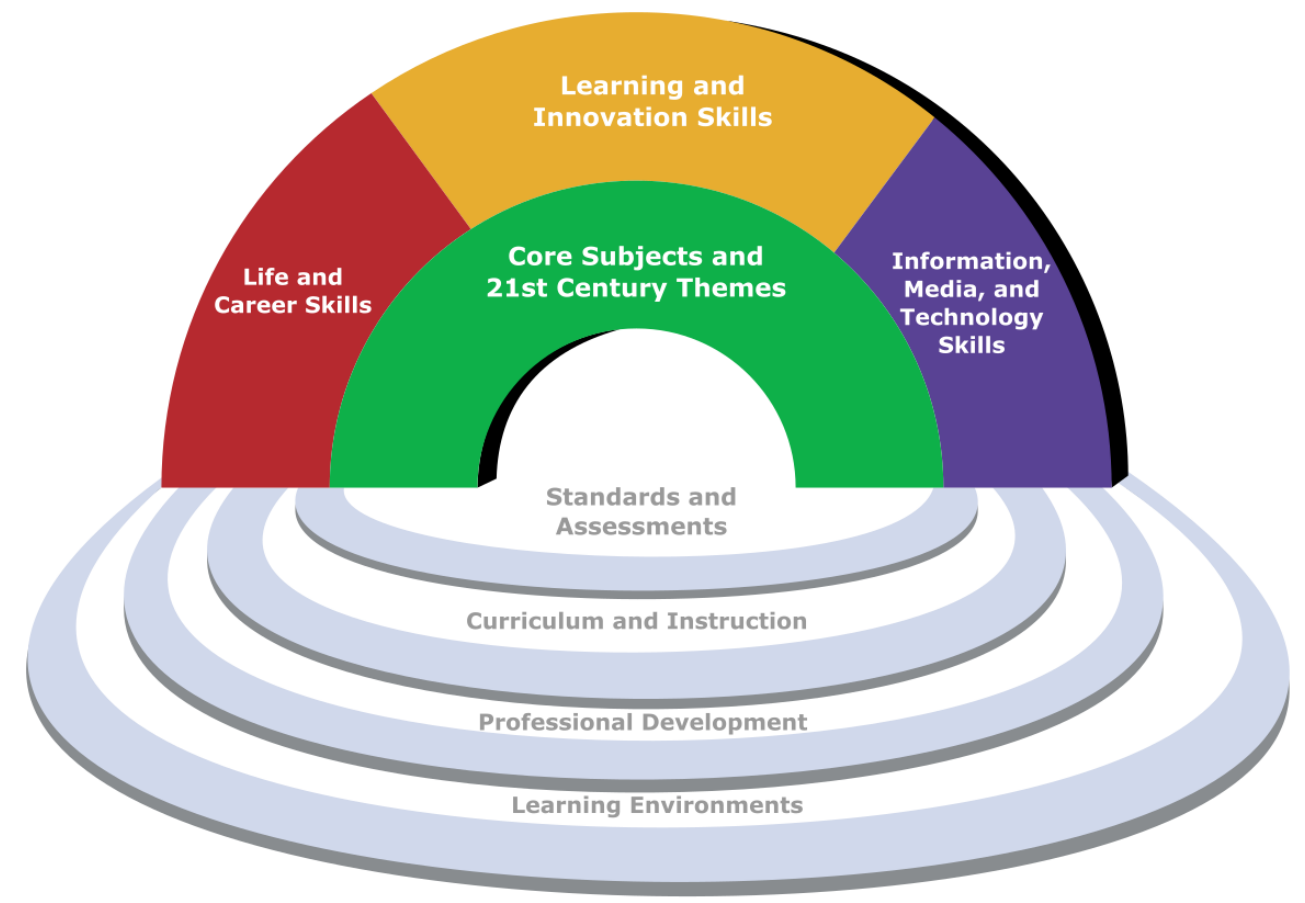

Figure 1. Framework For 21st century Learning

\section{Problem Statement}

Malaysia moving towards turning out to be propelled country with high pay economy, there are requirements to redesign the nature of workforce to fulfill the business needs and for society to accomplish better instruction and educated specialists. Aptitudes hole between industry prerequisite and abilities acquired by Technical and Vocational Education and Training (TVET) graduates is one of the primary issues that should be tended to with more prominent collaboration from industry with regards to improving alumni versatility to the business. The business educated that the quality regarding their TVET workforce is either normal or underneath. The constrained understanding of instructors could likewise be one of the potential explanations for graduates' restricted attention to down to earth application just as availability to meet industry's expert and specialized necessities.

Accordingly, solid commitment with the industries as curriculum development are essential in decreasing the aptitudes hole to make progressively significant TVET graduates for the industry. This study is imperative to inspect the general issue from a more extensive viewpoint that incorporates affectability studies to temporary job model that can be utilized in the development of abilities for employability for the ongoing workplace. The organization study is done in customary situations that are illustrative of genuine working 
situations by considering the understudies execution before temporary job program and upgrade assessment in the WBL mode. Customarily, understudies experience the temporary job program with any industries related and these uncovered understudies with the odds of landing errands outside their position scope.

\section{Methodology}

The research design is an important element in the study were able to help and guide researchers towards getting the right information and data in the study. The preferred approach would provide findings that are valid and reliable for achieving the objectives of the study and answer the research questions that have been expressed. (Cooper and Schindler ,1998) states that the design of the study is the design and structure of investigation provided for answers to all of the research questions. Whereas by (Ahmad Mahdzan ,2002) pointed out that the design of the study is that all steps or procedures taken to achieve all the goals of the study.

The aim of this study is to to reduce the gap between institution and industry by designing additional curriculum. In order to achieve this aim, the study was conducted qualitatively in the form of a document review. Several previous study reports, conference proceedings, and journals have been referred to as a literature review, and analysed with the data collected using a matrix table (Strauss \& Corbin, 1990).

Based on Sallabas (2013) and Best \& Kahn (1998), the document review method is the most appropriate tool to collect information in a qualitative study. Moreover, Onwuegbuzie, Leech, \& Collins (2012)) believe that the variables relevant to the topic can be identified by conducting a quality. review of the literature. This technique was used, because it is an organized method of reviewing and evaluating paper documents and electronic resources. Literature studies from journals, reports, and working papers were used as materials and resources for our document analysis.

\section{Results and Discussions:}

Knowledge and solid skill was required to process an effective teaching and learning. Lecturer is a class responsible for teaching students in the subject's technical skills either in terms of theory and practical. Mastery of skills, which are the core components of technical skills by lecturers will be able to provide optimal learning among the students. Therefore, students will be able to obtain the necessary guidance and not merely dominate the headings in technical skills subjects even produce quality products. Through this literature review, proved that in addition to lecturers and students, teaching aids also strongly needed especially during the demonstration.

This part reviews a number of significant work from previous research in graduate employability and the other factors related. In addition, the advantages and drawbacks of the existing system have also been highlighted, as well as the limitations of the existing work were addressed. It is the ultimate aim of the research work presented in this report, to address the limitations presented in the previous section with an efficient means of providing efficient implementation of structured internship program and work out to enhance the graduate employability by efficiently utilise the opportunities and at the same time enhancing the skills for employability as illustrated in Figure 1.

From the structured internship framework, polytechnic and industries should continue to promote and expand opportunities for students to access work-based learning. One of the most vital estimates polytechnic can receive to elevate employability is to incorporate appropriate integrated placements, internships and work based learning opportunities of significant period into their courses. On the other hands, by utilizing these approaches, attention to the humanities courses could also benefit from greater use of the framework. These experiential opportunities require careful planning and time for reflection must be inherent in if they are to be an effective way of providing polytechnic's students with relevant employment skills, knowledge and awareness of industries working culture. They also call for viable, sustained and equitable partnerships between polytechnic and industries.

Structured internship programmes aim to develop and authorize or perceive students' experiential and work-related learning are prescribed. These programmes are viewed as significant in light of the fact that they encourage students' access to work-based learning activities in polytechnics and work-based opportunities such as placements after completed the internship. However, placements and work-related and work-based experiences need to be documented so that students can offer industries evidence of their capacities and both technical and soft skills. Meanwhile, from the desktop study and review depicted as in figure 3 where industries and both polytechnic's students and lecturers found that there are attributes, skills and knowledge and intellectual capability elements that are required for explicit jobs. 


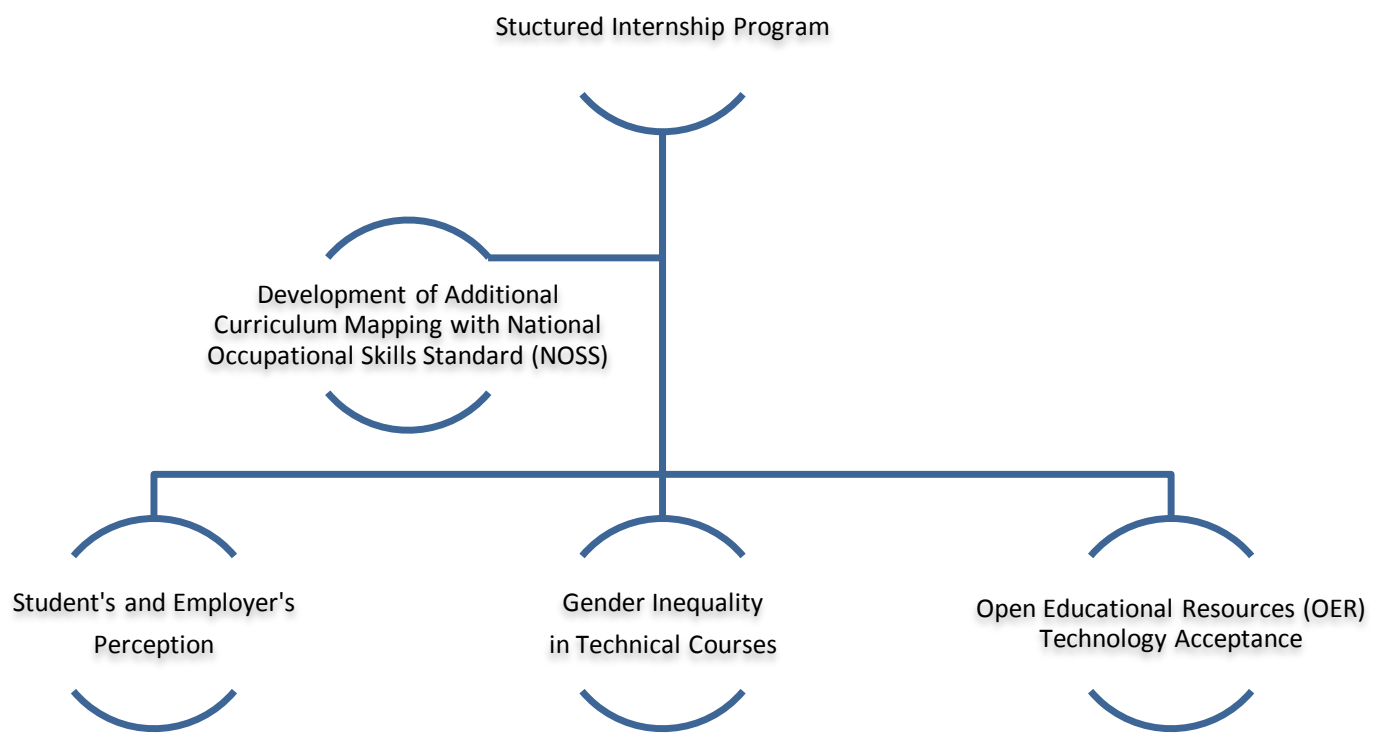

Figure 2. Implementation of Structured Internship Program were:

In addition, combinations of transferable skills were likewise considered especially significant. These

- $\quad$ Team working

- $\quad$ Problem solving

- $\quad$ Self-management

- Knowledge of the business

- Literacy and numeracy relevant to the post

- $\quad$ ICT knowledge

- Good interpersonal and communication skills

- $\quad$ Ability to use own initiative but also to follow instructions

- Leadership skills where necessary

In addition to these skills, industries also highlighted the need for particular attitudes and outlooks including motivation, tenacity, and commitment

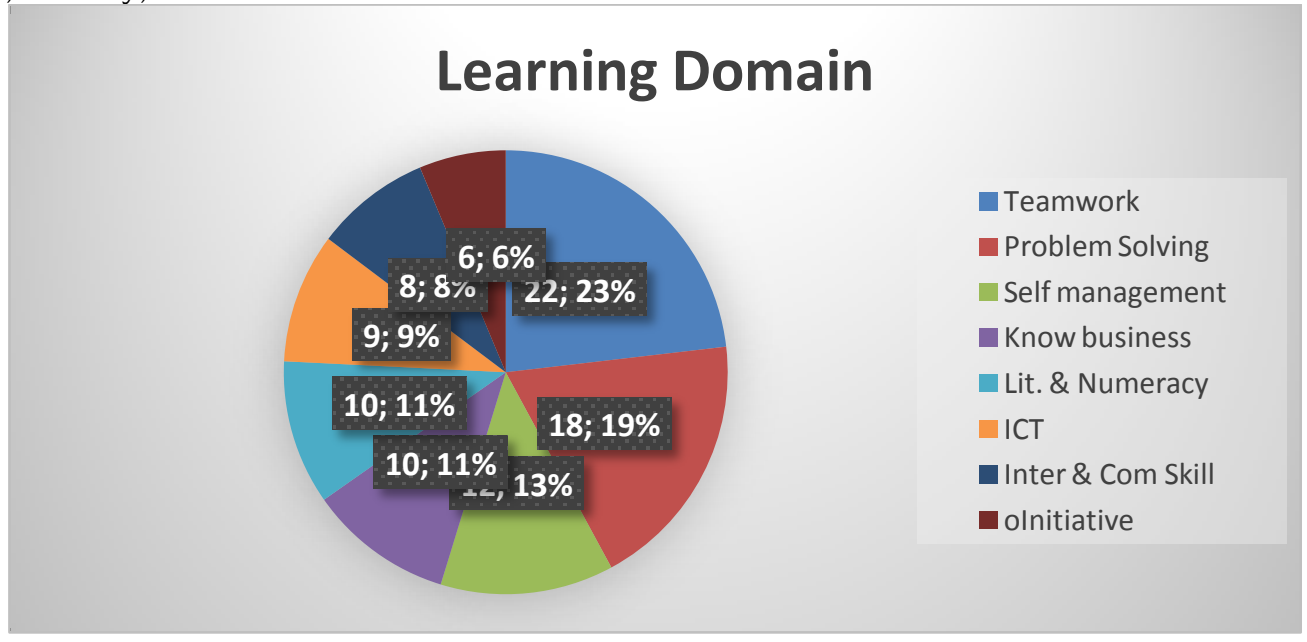

Figure 3: Readiness Skills need in Industries 


\section{Conclusions}

The mismatch between the skills required by industries and the skills possessed by the graduates is one of the causes of unemployment (Husain, Rasul, Mustapha, Malik, \& Abd Rauf, 2013; Shutt, Iles, \& Zhu, 2010). Askill gap report in 2019 found that nearly half of the industries surveyed expressed that existing employees lacked work ethics and selfmanagement skills, such as attendance and punctuality. In addition, $46 \%$ of industries reported that their employees lacked problem solving skills (Hasan, Yasin, \& Yunus, 2016). Based on previous research that has been discussed before, researcher concludes that student must be competent if knowledge, skill and attitude will be perform and expert while working in the industry. Some past research shows that efficiency is considered external behaviours, consists of knowledge, skills, and attitudes (Shyr, 2012).

Although employability seems to receive considerable attention and scholarly debate in the literature, there are still notable gaps around evidence that links successful attainment of work-ready skills to the impact graduate employability and employment, including the longterm career implications. There are few available longitudinal studies exploring employability. Furthermore, there is a need to consider curriculum redesign with employability foundational to the curriculum, where students can identify and explicitly link to their learning activity to a desirable graduate competency. Advancing the education provided to post-secondary students is integral to effectively preparing them for a life-long career in their chosen field. Therefore, it is likely that employability, despite the considerable discussion already in the literature, will remain a key research direction and focus of scholarly debate for some time yet.

\section{References}

Best, J. W., \& Kahn, J. V. (1998). Research in Education. (Edisi ke-8). Needham Heights: Allyn and Bacon.

Betsy, B., Andrew, V., \& Andrea, B. (2013). How Career and Technical Education Can Help Students Be College and Career Ready : A Primer.

Burke, C., Scurry, T., Blenkinsopp, J., \& Graley, K. (2016). Critical perspectives on graduate employability. In M. T. \& L. H. (Eds.) (Ed.), Graduate employability in context (pp. 87-107). https://doi.org/10.1057/978-1137-57168-7_4

Hasan, A., Yasin, S. N. T. M., \& Yunus, M. F. M. (2016). Technical competency for diploma in mechatronic engineering at polytechnics Malaysia. International Review of Management and Marketing, 6(4S), 196-199.

Husain, M. Y., Rasul, M. S., Mustapha, R., Malik, S. A., \& Abd Rauf, R. A. (2013). Tahap Kemahiran Employability Pelajar Kejuruteraan dari Perspektif Majikan. Jurnal Teknologi, 1, 31-39.

Kelly, A. V. (2009). The curriculum: Theory and practice. SAGE Publications.

McKernan, J. (2008). Curriculum and Imagination: Process Theory, Pedagogy and Action Research. Milton Park: Routledge.

Onwuegbuzie, A. J., Leech, N. L., \& Collins, K. M. T. (2012). Qualitative analysis techniques for the review of the literature. (17th ed.).

Sallabas, M. E. (2013). Analysis of narrative texts in secondary school textbooks in terms of values education. Educational Research and Reviews, 8(8): 361-366. doi:10.5897/ERR12.190. Educational Research and Reviews, 8(8), 361-366. https://doi.org/10.5897/ERR12.190.

Shutt, J., Iles, P., \& Zhu, X. (2010). Employability, skill and talent management in Zhejiang province. Journal of Chinese Entrepreneurship, 3(1), 24-35.

Shyr, W. (2012). Industry-Oriented Competency Requirement For Mechatronics Technology In Taiwan. TOJET: The Turkish Online Journal of Educational Technology, 11(4), 195-203.

Strauss, A., \& Corbin, J. (1990). Basics of qualitative research: Grounded theory procedures and techniques. Newburry Park: CA: Sage. 